\title{
Influence of the carrier material on the stability of chokeberry juice microcapsules**
}

\author{
Emilia Janiszewska-Turak (10*, Andrzej Sak, and Dorota Witrowa-Rajchert \\ Department of Food Engineering and Process Management, Faculty of Food Sciences, Warsaw University of Life Sciences (SGGW), \\ Warsaw, Nowoursynowska 159c, 02-776 Warsaw, Poland
}

Received February 11, 2019; accepted June 5, 2019

\begin{abstract}
Anthocyanins from chokeberry show significant health-promoting properties. Unfortunately, they are sensitive to environmental factors and require protection. Spray drying with carrier materials is a viable method used to protect sensitive ingredients. However, the choice of carrier material in this process is crucial. The aim of this study was to examine the influence of the carrier type on the dry matter, density, colour, hygroscopicity and anthocyanin content in powders after spray drying and storage. Low-crystallized maltodextrin, arabic gum, mixtures of maltodextrin and arabic gum $(1: 1 ; 2: 1 ; 3: 1)$ and rice starch were used as carriers. All powders showed a high dry matter content (96-99\%) and low hygroscopicity (0.136-0.2 $\mathrm{g} \mathrm{H}_{2} \mathrm{O} \mathrm{g} \mathrm{g}^{-1} \mathrm{~d} . \mathrm{m}$.), indicating a good potential for the protection of microencapsulated anthocyanins during storage. However, after storage tests for anthocyanin content, the optimal carrier was found to be maltodextrin.

Keywords: encapsulation, spray drying, carriers, hygroscopicity, anthocyanins
\end{abstract}

\section{INTRODUCTION}

In recent years, food consumers have encouraged food companies to use food colourants from natural sources such as plants/vegetables/fruits. Natural colourants usually contain more than one active colourant and other active substances, which are beneficial for human health (Samoticha et al., 2016). One group of such colourants is the anthocyanins, water-soluble vacuolar pigments with varying $\mathrm{pH}$ values, that may be used as red, purple, or blue colourants. Food plants rich in anthocyanins include cranberry, blueberry, raspberry, elderberry, blackcurrant, chokeberry and others. Moreover, anthocyanins are bio-

*Corresponding author e-mail: emilia_janiszewska_turak@sggw.pl **This work was co-financed by a statutory activity subsidy from the Polish Ministry of Science and Higher Education for the Faculty of Food Sciences of Warsaw University of Life Sciences (2018). active substances, which may influence human health (Rodriguez-Mateos et al., 2014). Among the berries, chokeberry (Aronia melanocarpa L.), which is naturally grown in Canada and the southern part of the USA, but also in Russia, Poland and Germany, deserves special attention, being linked to the highest content of anthocyanins and other polyphenols compared to other berries, e.g. elderberries or blackcurrant berries (Veberic et al., 2015; Cujic et al., 2017). In chokeberries, two phenolic acids (chlorogenic and neochlorogenic), four anthocyanins (3-O-galactoside, 3-O-glucoside, 3-O-arabinoside and 3-O-xyloside of cyanidin), five quercetin derivatives and a high content of vitamin C were found (Oszmiański and Wojdyło, 2005; Horszwald et al., 2013). It has been reported that the total phenolic content in chokeberries is more than $20 \mathrm{mg} \mathrm{g}^{-1}$ (gallic acid equivalents) (Oszmiański and Wojdyło, 2005), and the anthocyanin level is usually about $2080 \mathrm{mg} 100 \mathrm{~g}^{-1}$ of berries (Horszwald et al., 2013). Because of this, chokeberry extracts show significant health-promoting properties such as anti-diabetic and anti-inflammatory effects, as well as reducing the likelihood of heart diseases and other cardiovascular diseases from developing (Gawałek et al., 2017). In most cases, chokeberry fruit are used for juice or dried fruit production, because their sour taste is not acceptable to most consumers (Cujic et al., 2017).

Unfortunately, natural colourants are more sensitive to temperature changes, $\mathrm{pH}$, presence of oxygen, light, ultraviolet and gamma radiation than synthetic ones, and that is the main limitation of their use in the food industry (Domian et al., 2015). Because of this, the food industry has focused attention on the drying process, especially spray drying

(C) 2019 Institute of Agrophysics, Polish Academy of Sciences 
with the use of carrier materials (Chranioti et al., 2015). After spray drying, the colourant, which is in a powdered form, is protected from environmental factors and thus the final product is more stable. It is widely known that drying vegetable or fruit juices without any carrier is impossible, due to the presence of low molecular weight components, such as sucrose, fructose and glucose. Without the use of a carrier material the obtained powder is sticky, hygroscopic and hard to use. In order to obtain any useable powder the addition of a carrier material to the juice is necessary (Janiszewska, 2014). In this study, maltodextrin (MD), arabic gum (AG) and rice starch (S) were chosen as the most commonly used carriers for the spray drying of fruit juices in the food industry (Costa et al., 2015; JaniszewskaTurak et al., 2017). Moreover, mixtures of these carriers are usually better for protection than the usage of one carrier material only (Fazaeli et al., 2012). It should be noted that the protection of active substances (anthocyanins in chokeberries) during the spray-drying process and after storage is crucial. Moreover, certain physical properties such as hygroscopicity, dry matter, and water activity may influence the anthocyanin content during storage.

In order to verify the observations made by scientists concerning other pigments and to solve the problems concerning the maximum possible concentrations of the pigment in powder as well as the possible future storage issues of chokeberry anthocyanin colourant powder, the aim of the study was to examine the relationship between the carrier type and the amount of anthocyanins in the powder as well as selected physical properties of powders after the spray drying process. The scope of the study included: a) testing drying solutions with different types of carriers under the same spray drying conditions, b) testing selected physical and chemical properties of the obtained chokeberry juice powder, and c) testing selected physical and chemical properties after storage in different conditions. The data obtained in this study may be a useful guide for the proper storage of dried chokeberry juice on a commercial scale.

\section{MATERIALS AND METHODS}

Chokeberry juice was prepared from concentrated juice $\left(55.2^{\circ} \mathrm{Bx}\right)$ from the company Agros-Tarczyn (Tarczyn, Poland). Low-crystallized maltodextrin with $\mathrm{DE}=15.6$ (MD) (PPS "PEEPES" S.A., Łomża, Poland), arabic gum type 4639 (AG) (Willy Benecke, Hamburg, Germany) and rice starch Remyline AX DR (S) (BENEO-Remy, LeuvenWijgmaal, Belgium) were used as the carriers.

In order to obtain a solution for spray drying, concentrated juice was diluted to $12^{\circ} \mathrm{Bx}$ and the carrier material was added. To compare microcapsules from different carrier materials, the solid soluble content in the solutions was brought to $30^{\circ} \mathrm{Bx}$ by adding the appropriate amount of the various carrier materials (the solid soluble content was
Table 1. Schema of solution preparation for the experiment

\begin{tabular}{cllll}
\hline $\begin{array}{c}\text { Carrier } \\
\text { material/ } \\
\text { sample } \\
\text { number }\end{array}$ & Juice & MD & AG & $\mathrm{S}$ \\
\hline 1 & 2 & 3 & 0 & 0 \\
2 & 2 & 0 & 3 & 0 \\
3 & 2 & 0 & 0 & 3 \\
4 & 2 & 1.5 & 1.5 & 0 \\
5 & 2 & 0.75 & 2.25 & 0 \\
6 & 2 & 2.25 & 0.75 & 0 \\
7 & 2 & 1.5 & 0 & 1.5 \\
8 & 2 & 0.75 & 0 & 2.25 \\
9 & 2 & 1.5 & 0 & 1.5 \\
10 & 2 & 0 & 1.5 & 1.5 \\
11 & 2 & 0 & 2.25 & 0.75 \\
12 & 2 & 0 & 0.75 & 2.25 \\
13 & 2 & 1 & 1 & 1 \\
\hline
\end{tabular}

$\mathrm{MD}$ - maltodextrin, AG - arabic gum, and $\mathrm{S}$ - rice starch.

measured using a digital refractometer, PAL-3, ATAGO, Tokyo, Japan). The value of $30^{\circ} \mathrm{Bx}$ of solid soluble content in the solution was chosen on the basis of previous tests, in which the ratio of 2:3 juice dry matter:carrier was found to be the most suitable for spray drying. The schema of carrier addition is presented in Table 1 .

All solutions with $\mathrm{AG}$ and $\mathrm{S}$ were stored for $24 \mathrm{~h}$ prior to spray drying in order to achieve the complete hydrogenation of the carrier and its homogeneity across the juice.

Drying was carried out in the semi-industrial spray drier LAB S1 (Anhydro, Copenhagen, Denmark). Based on pre-tests for these materials (unpublished) the following parameters of the drying process were chosen: a spray disk speed of 39,000 rpm and a raw material flux rate of $1 \cdot 10^{-6} \mathrm{~m}^{3} \mathrm{~s}^{-1}$. The drying process was carried out using the co-current method and the inlet air temperature was set at $180^{\circ} \mathrm{C}$ at a constant air flow of $0.055 \mathrm{~m}^{3} \mathrm{~s}^{-1}$. The powder was collected in the cyclone and then transferred to glass twist-off jars. All of the measurements were performed after the spray-drying process and after 9 weeks of storage. The experiment was performed in duplicate for each carrier.

The dry matter (DM) content of the powders and juices was measured using the gravimetrical method. A powder sample of $1 \mathrm{~g}$ was dried at $105^{\circ} \mathrm{C}$ to achieve a constant weight. In the case of juice, $1.5 \mathrm{~g}$ was placed on a twisted strip of tissue paper located in a dish and dried at $70^{\circ} \mathrm{C}$ to achieve a constant weight. DM was measured in triplicate for each dried sample and juice.

In order to investigate the hygroscopic properties, batches of $1 \mathrm{~g}$ of powder were placed in a desiccator filled with $\mathrm{NaCl}$ at $20^{\circ} \mathrm{C}\left(\mathrm{a}_{\mathrm{w}}=0.75\right)$. Adsorption was analysed over an $80 \mathrm{~h}$ period, by determining the mass of the sample 
after 1, 2, 5, 24, 48 and $80 \mathrm{~h}$. Changes in the hygroscopic properties of the powders were described by the kinetic equation presented by Janiszewska et al. (2013):

$$
\frac{m_{\tau}}{m_{0}}=A+B\left(1-\frac{1}{1+B C \tau}\right),
$$

where: $A, B, C$-coefficients of the equation, $\tau$ - time (h), $m_{\tau}$ - weight after time $\tau(\mathrm{g}), m_{0}-$ initial weight $(\mathrm{g})$.

The apparent density was measured in a helium pycnometer - Quantachrome's Stereopycnometer (Boyton Beach, USA). Loose bulk density was determined using a vibrating volumeter (STAV2003 Engelsmann AG Ludwigshafen, Germany). Porosity was calculated from the equation presented by Janiszewska et al. (2010). These tests were performed in triplicate.

For measuring the colour components of the powders, a Minolta CR-A70 colorimeter (New Jersey, USA) was used. The measurement was performed using the CIE 1976 system and the calibration was carried out for a white pattern $\left(L^{*} 92.49, a^{*} 1.25, b^{*}-1.92\right)$. Measurements were performed in five replications. The measurement was performed for a black plate with a glassy hole in the middle of the measuring cell, with standard illumination $\mathrm{C}$.

The total monomeric anthocyanin concentration was analysed using the $\mathrm{pH}$ differential method according to Giusti and Wrolstad (2001). The extract of chokeberry juice, solutions and powders were diluted with two buffer solutions at $\mathrm{pH} 1$ and $\mathrm{pH} 4.5$. Cy-3-G $\left(\mathrm{MW}=449.2 \mathrm{~g} \mathrm{~mol}^{-1}\right)$, was used as a standard with a molar absorptivity coefficient of $26900\left(\mathrm{~L} \mathrm{~mol}^{-1} \mathrm{~cm}^{-1}\right)$. The results were expressed in the form of $\mathrm{mg}$ of Cy-3-G per L (Horszwald et al., 2013).

In order to prepare an extract of anthocyanins $0.5 \mathrm{~g}$ of chokeberry juice, solution or chokeberry powder was weighed into a Falcon tube and $15 \mathrm{~mL}$ of reagent was added. The extraction reagent consisted of $0.1 \mathrm{~N}$ hydrochloric acid and $80 \%$ ethanolic solution $(15: 85 \mathrm{v} / \mathrm{v})$. The content was homogenized and shaken for $10 \mathrm{~min}$ with a speed of $2000 \mathrm{rpm}$. Magnesium carbonate was added to improve precipitation during centrifugation, which was carried out for $5 \mathrm{~min}$ with a velocity of $6000 \mathrm{rpm}$. After centrifugation, the supernatant was collected into a volumetric flask. The volumetric flask was filled with reagent and the extract was used for anthocyanin determination. Two extracts were prepared for each type of treatment.

For the anthocyanin content analysis, $1.5 \mathrm{~mL}$ of extract was transferred into two glass tubes. $3.5 \mathrm{~mL}$ of buffer at pH 1.0 (0.025 M potassium chloride) was added into the first tube and the second tube consisted of buffer at $\mathrm{pH}$ $4.5(0.4 \mathrm{M}$ sodium acetate). Mixtures were stirred and left in the darkness at room temperature. After $30 \mathrm{~min}$ of incubation, the absorption was measured at 510 and 700 nm (Thermo Spectronic Helios Gamma, Thermo Fischer Scientific, USA). All extracts were analysed in triplicate.

Absorbance was calculated from the following equation:

$$
\mathrm{A}=\left(\mathrm{A}_{510}-\mathrm{A}_{700}\right)_{\mathrm{pH} 1}-\left(\mathrm{A}_{510}-\mathrm{A}_{700}\right)_{\mathrm{pH} 4.5} .
$$

Monomeric anthocyanins pigment $M A\left(\mathrm{mg} \mathrm{L}^{-1}\right)$ was calculated from the following equation:

$$
M A=\frac{A \cdot M W \cdot D F \cdot 1000}{\varepsilon^{\cdot} l},
$$

where: $M W$ - molecular weight of cyanidin-3-glucoside (449.2 $\left.\mathrm{g} \mathrm{mol}^{-1}\right), D F$ - dilution factor, 1000 - factor for converting $\mathrm{g}$ to $\mathrm{mg}, \varepsilon-$ molar absorptivity of cyanidin3-glucoside $26900 \mathrm{~L} \mathrm{~mol}^{1}$ ) $\mathrm{cm}^{-1}, l$ - path length of $1 \mathrm{~cm}$.

All powders were stored for 9 weeks at three temperatures, 5,25 and $35^{\circ} \mathrm{C}$, in a dark place. After that time, colour and monomeric anthocyanins were tested as described in the methodology.

Data are presented as mean \pm standard deviation. The significance of the inter-group differences was determined by a one-way analysis of variance (ANOVA), calculated with Statistica v. 12.5 software. Individual group differences were identified using the Tukey (HSD) multiple range test at a significance level of 0.05 . Coefficients of determination $\left(\mathrm{R}^{2}\right)$ and root mean square errors (RMSE) were used in this study to determine the goodness of fit. Fitting hygroscopicity to the equations was performed using Table Curve 2D v 5.01 (SYSTAT Software Inc). Additionally, Pearson's correlation coefficient was calculated in order to evaluate the dependence between the anthocyanin content and the colour parameters.

\section{RESULTS AND DISCUSSION}

In juice and in its solutions with carriers the solid soluble content was measured. This value was treated as the main property of the solutions and should be the same for each solution. From the measurements, it was noted that the solid soluble content was in the range $30.1-30.3^{\circ} \mathrm{Bx}$. For diluted juice, the solid soluble content was $12 \pm 0.3^{\circ} \mathrm{Bx}$ and the dry matter content was $8.6 \pm 0.5 \%$ (Table 2 ).

All of the powders obtained were characterized by a dry matter content in the range of $97-98 \%$ (Table 2). Such a high dry matter content of the powders is important during storage for these kinds of products (da Silva Carvalho et al., 2016). Statistically significant differences between the dry matter content values were not found. It was observed that carrier material had influenced the apparent density, bulk density and porosity (Table 2). The highest values of the apparent and loose bulk density were observed for powders with rice starch and the lowest one for powders with maltodextrin (MD).

Porosity was in the range of $59-72 \%$, the lowest for arabic gum and the highest for the powder with maltodextrin as a carrier. The addition of arabic gum to the maltodextrin or rice starch caused a decrease in porosity values. This may be related to the size of the particles, which is correlated to the type of carrier material. After spray drying, 
Table 2. Selected physical properties of chokeberry powder and juice

\begin{tabular}{|c|c|c|c|c|}
\hline $\begin{array}{l}\text { Carrier/selected } \\
\text { physical } \\
\text { parameter }\end{array}$ & $\begin{array}{c}\text { Dry matter } \\
(\%)\end{array}$ & $\begin{array}{l}\text { Apparent density } \\
\qquad\left(\mathrm{kg} \mathrm{m}^{-3}\right)\end{array}$ & $\begin{array}{l}\text { Porosity } \\
\text { (\%) }\end{array}$ & $\begin{array}{l}\text { Bulk density } \\
\qquad\left(\mathrm{kg} \mathrm{m}^{-3}\right)\end{array}$ \\
\hline Juice & $8.6 \pm 0.5$ & - & - & - \\
\hline MD & $98.5 \pm 0.2 \mathrm{a}$ & $1131 \pm 23 a$ & $71 \pm 0.2 \mathrm{ef}$ & $330 \pm 6 \mathrm{a}$ \\
\hline $\mathrm{AG}$ & $98.3 \pm 0.1 \mathrm{a}$ & $1262 \pm 9 \mathrm{c}$ & $59 \pm 0.6 \mathrm{a}$ & $512 \pm 5 \mathrm{e}$ \\
\hline S & $97.7 \pm 0.2 \mathrm{a}$ & $1540 \pm 22 \mathrm{f}$ & $72 \pm 0.4 \mathrm{ef}$ & $427 \pm 3 b c$ \\
\hline $\mathrm{MD}: \mathrm{AG}=1: 1$ & $97.1 \pm 0.5 \mathrm{a}$ & $1252 \pm 8 \mathrm{c}$ & $62 \pm 0.8 \mathrm{abc}$ & $475 \pm 12 \mathrm{~cd}$ \\
\hline $\mathrm{MD}: \mathrm{AG}=1: 3$ & $97.5 \pm 0.3 \mathrm{a}$ & $1236 \pm 9 c$ & $61 \pm 2.3 \mathrm{ab}$ & $484 \pm 25 \mathrm{de}$ \\
\hline $\mathrm{MD}: \mathrm{AG}=3: 1$ & $97.7 \pm 0.4 \mathrm{a}$ & $1172 \pm 5 b$ & $64 \pm 0.5 b c$ & $425 \pm 4 b c$ \\
\hline $\mathrm{MD}: \mathrm{S}=1: 1$ & $95.9 \pm 3.2 \mathrm{a}$ & $1450 \pm 14 \mathrm{e}$ & $72 \pm 1.4 \mathrm{f}$ & $406 \pm 19 b$ \\
\hline $\mathrm{MD}: \mathrm{S}=1: 3$ & $98.3 \pm 0.2 \mathrm{a}$ & $1505 \pm 16 f$ & $74 \pm 0.13 f$ & $463 \pm 25 \mathrm{~cd}$ \\
\hline $\mathrm{MD}: \mathrm{S}=3: 1$ & $98.3 \pm 0.1 \mathrm{a}$ & $1358 \pm 8 d$ & $66 \pm 0.7 \mathrm{~cd}$ & $483 \pm 6$ de \\
\hline AG:S=1:1 & $96.9 \pm 0.4 \mathrm{a}$ & $1434 \pm 7 \mathrm{e}$ & $63 \pm 1.4 \mathrm{abc}$ & $530 \pm 19$ de \\
\hline$A G: S=1: 3$ & $97.7 \pm 0.1 \mathrm{a}$ & $1441 \pm 11 \mathrm{e}$ & $68 \pm 1.7 \mathrm{de}$ & $391 \pm 20 b$ \\
\hline $\mathrm{AG}: S=3: 1$ & $97.2 \pm 0.2 \mathrm{a}$ & $1367 \pm 12 d$ & $65 \pm 0.4 \mathrm{bcd}$ & $468 \pm 12 \mathrm{~cd}$ \\
\hline MD:AG:S=1:1:1 & $97.6 \pm 0.5 \mathrm{a}$ & $1367 \pm 17 d$ & $63 \pm 3.0 \mathrm{abc}$ & $501 \pm 35 \mathrm{de}$ \\
\hline
\end{tabular}

$\mathrm{a}, \mathrm{b}, \mathrm{c}, \mathrm{d}$ - values with different letters in the same column differ significantly $(\mathrm{p}<0.05)$. Explanations as in Table 1.

arabic gum produces a smoother surface than those particles c reated with maltodextrin (Gawałek et al., 2017). The observation of apparent density and loose bulk density may suggest that the size of the particles with AG was smaller than those with MD or starch.

Tonon el al. (2010) obtained similar values for acai juice powders with starch and maltodextrin but different from those for AG powders. Some authors suggested that a lower porosity is better for storage, because of the lower density of empty spaces between the particles. This is related to the lower rate of the degradation of active ingredients after exposure to air (Cavalcanti et al., 2011). It was confirmed in our storage tests that $\mathrm{AG}$ powders were more stable than those with starch.

Hygroscopicity is usually defined as the capacity of powder to absorb moisture from the environment. This parameter may show the tendency of the powder to stickiness or caking during exposure to an environment with high humidity (Yamashita et al., 2017). Moreover, in powder intended for the food industry, hygroscopicity may been related to the porosity of the powder or to the amorphous glassy state of sugars present in foods (Roos, 2002). Accordingly, the hygroscopicity of the chokeberry juice particles was tested in order to show its physical stability in the case of storage under the most commonly used conditions, as represented by a water activity close to that used in the food industry during storage. The kinetics of vapour adsorption is shown in Fig. 1, by means of the relative increment in water mass as a function of time. Chokeberry juice powders with a mixture of $A G$ and $\mathrm{S}$ adsorbed water vapour at the highest rate, so that after $80 \mathrm{~h}$ they adsorbed 0.199-0.203 $\mathrm{g} \mathrm{H}_{2} \mathrm{O} \mathrm{g}^{-1}$ d.m. The slowest rate was registered for checkerberry juice powders with maltodextrin, which adsorbed in $16808 \mathrm{~h} 0.107 \mathrm{~g} \mathrm{H}_{2} \mathrm{O} \mathrm{g}^{-1} \mathrm{~d} . \mathrm{m}$. The goodness of fit experimental data to equation 1 was at a high level $\left(\mathrm{R}^{2}=0.996-0.999\right)$ with RMSE below $0.4 \%$, which means that the experimental results were perfectly described by the selected equation (Table 3 ).

The relative water mass increments at equilibrium were calculated from the kinetic equation presented by Janiszewska et al. (2013) (Table 3). None of the tested powders achieved the equilibrium values. The highest equilibrium values were observed for powders based on AG. The lowest values were obtained for powders based on MD (100\%) and its mixture with a higher percent of MD. Janiszewska-Turak et al. (2017) observed the same correlation for carrot powders.

After analysing the presented graph (Fig. 1), four different types of water intake behaviour could be identified. The slowest water intake was observed for powders based on a higher percentage of $\mathrm{MD}$ (MD, $\mathrm{MD}: \mathrm{AG}=3: 1$, $M D: A G=1: 1)$. The next group was based on $A G(A G$, $M D: A G=1: 3)$, in which the adsorption was a little bit faster than in the first group. The third and fourth groups were based on rice starch and its mixtures with MD and AG. In these groups, the fastest water intake was observed. These results may be correlated with particle dry matter content (Bazaria and Kumar, 2016). The higher water gradient between the product and the surrounding air favours a high hygroscopicity value. From a storage point of view it is better if the water intake is slower and reaches lower values, this was confirmed in our experiments with starch powders (Fig. 3). After $80 \mathrm{~h}$ in a desiccator the powder with starch with $a_{w}=0.75$ appeared to be the best of all the materials 


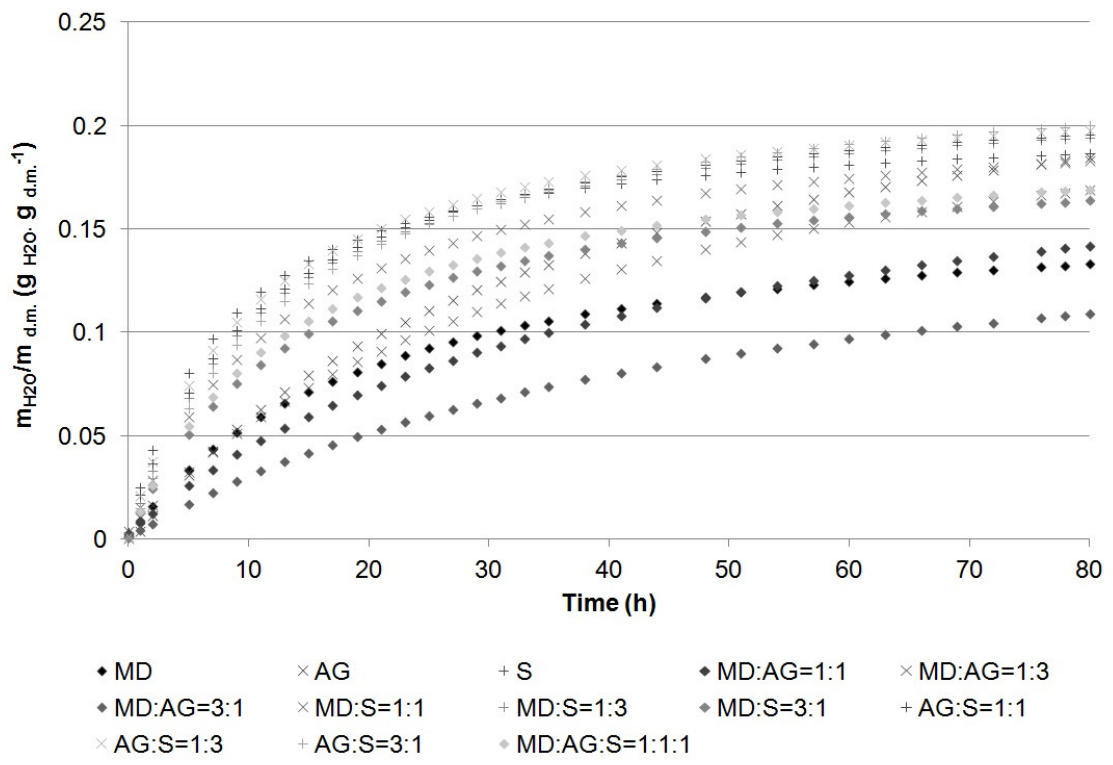

Fig. 1. Hygroscopicity of chokeberry microcapsules at $\mathrm{a}_{\mathrm{w}}=0.7$.

tested (Fig. 2). Phisut (2012) also stated that the differences in water adsorption may be explained by the chemical structure of the applied drying carrier. The phenomenon of water adsorption by carbohydrates may be explained by the formation of links between the molecules of hydrogen in water and the hydroxyl groups in the amorphous regions of the substrate.

In chokeberry juice, the total amount of monomeric anthocyanins was $1430 \pm 14(\mathrm{mg} C y-3-\mathrm{G}) \mathrm{L}^{-1}$. In powders after spray drying, the value ranged from 612 (mg Cy-3-G)
$\mathrm{L}^{-1}$ for powder with MD:S=1:1 to 901-915 (mg Cy-3-G) $\mathrm{L}^{-1}$ for powders based on MD or AG only (Fig. 3). The highest values were observed for powders based on $\mathrm{MD}, \mathrm{AG}$ and its mixtures. The addition of rice starch to the juice as a carrier (alone or in mixtures with other carriers) caused a statistically significant decrease in anthocyanin content (Fig. 3), but a higher anthocyanin content was observed for rice starch in combination with $\mathrm{AG}$ rather than with $\mathrm{MD}$ as a carrier material.

Table 3. Hygroscopicity of chokeberry powders and coefficients for equation presented by Janiszewska et al (2014)

\begin{tabular}{|c|c|c|c|c|c|c|c|}
\hline \multirow{2}{*}{ Carrier type } & \multirow{2}{*}{$\begin{array}{c}\text { Hygroscopicity } \\
\text { after } 80 \mathrm{~h} \\
\left(\mathrm{~g}_{\mathrm{H}_{2} 0} \mathrm{~g}^{-1} \text { d.m.) }\right.\end{array}$} & \multicolumn{3}{|c|}{ Coefficients of equation } & \multirow{2}{*}{$\mathrm{R}^{2}$} & \multirow{2}{*}{$\begin{array}{l}R M S E \\
(\%)\end{array}$} & \multirow{2}{*}{$\begin{array}{l}\text { Equilibrium } \\
\text { value }\end{array}$} \\
\hline & & A & $\mathrm{B}$ & $\mathrm{C}$ & & & \\
\hline MD & $0.136 \pm 0.006 \mathrm{abc}$ & 0.0011 & 0.166 & 0.296 & 0.997 & 0.29018 & 0.167 \\
\hline AG & $0.178 \pm 0.003 \mathrm{cde}$ & -0.0038 & 0.266 & 0.113 & 0.997 & 0.35622 & 0.262 \\
\hline $\mathrm{S}$ & $0.188 \pm 0.001 \mathrm{cde}$ & 0.0025 & 0.202 & 0.617 & 0.999 & 0.19609 & 0.205 \\
\hline $\mathrm{MD}: \mathrm{AG}=1: 1$ & $0.141 \pm 0.003 \mathrm{~b}$ & 0.0026 & 0.209 & 0.119 & 0.999 & 0.14671 & 0.212 \\
\hline $\mathrm{MD}: \mathrm{AG}=1: 3$ & $0.167 \pm 0.011 b c$ & 0.0039 & 0.242 & 0.111 & 0.997 & 0.36311 & 0.246 \\
\hline $\mathrm{MD}: \mathrm{AG}=3: 1$ & $0.107 \pm 0.027 \mathrm{a}$ & 0.0006 & 0.174 & 0.119 & 0.998 & 0.18088 & 0.175 \\
\hline $\mathrm{MD}: \mathrm{S}=1: 1$ & $0.188 \pm 0.002 \mathrm{cde}$ & 0.0005 & 0.212 & 0.362 & 0.999 & 0.20357 & 0.213 \\
\hline $\mathrm{MD}: \mathrm{S}=1: 3$ & $0.193 \pm 0.000 \mathrm{cde}$ & -0.0009 & 0.222 & 0.406 & 0.999 & 0.18417 & 0.221 \\
\hline $\mathrm{MD}: \mathrm{S}=3: 1$ & $0.168 \pm 0.003 \mathrm{bcd}$ & 0.0006 & 0.192 & 0.368 & 0.998 & 0.25835 & 0.193 \\
\hline$A G: S=1: 1$ & $0.202 \pm 0.008 \mathrm{de}$ & 0.0034 & 0.219 & 0.406 & 0.999 & 0.22942 & 0.222 \\
\hline $\mathrm{AG}: \mathrm{S}=1: 3$ & $0.199 \pm 0.002 \mathrm{cde}$ & 0.0014 & 0.221 & 0.442 & 0.999 & 0.13625 & 0.222 \\
\hline $\mathrm{AG}: \mathrm{S}=3: 1$ & $0.203 \pm 0.008 \mathrm{e}$ & -0.0017 & 0.235 & 0.325 & 0.999 & 0.21222 & 0.233 \\
\hline MD:AG:S=1:1:1 & $0.175 \pm 0.025 \mathrm{cde}$ & -0.0009 & 0.197 & 0.398 & 0.996 & 0.38856 & 0.196 \\
\hline
\end{tabular}

Explanations as in Table 2. 


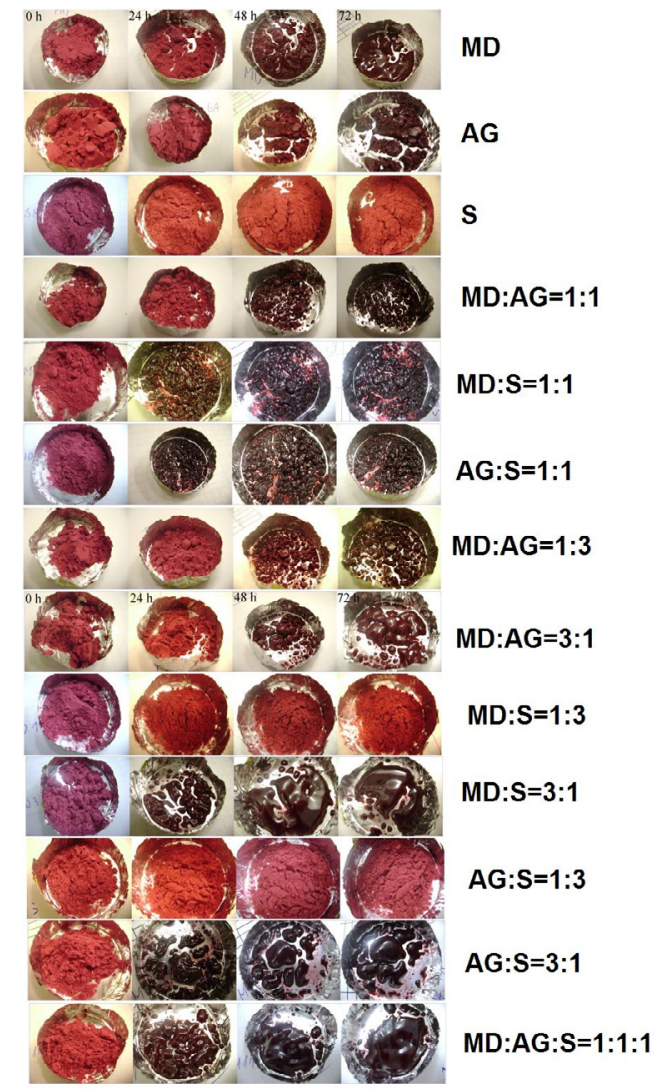

Fig. 2. Chokeberry powder after $1,24,48$ and $72 \mathrm{~h}$ in desiccators with $\mathrm{a}_{\mathrm{w}}=0.7$.
The colour of the particles is perceived to be the most important distinguishing feature of quality in the product and the initial factor that leads the consumer to choose a product. That is the reason for testing it and attempting to relate it to the total monomeric anthocyanin content. With knowledge of that correlation a simple test could enable food industry personnel to determine the appropriate amount of chokeberry powder to apply on the production line, e.g. to add to yoghurt (Jafari et al., 2017). In the present study article, no perfect correlation was found. However, the goodness of fit after spray drying for monomeric anthocyanin content to colour coefficients after drying was at a high level. Pearson's coefficient $r$ value for the correlation with $L^{*}$ was the lowest $(\mathrm{y}=-26.914 \mathrm{x}+2085.4, \mathrm{r}=0.49)$, while for colour coefficients $\mathbf{a}^{*}(\mathrm{y}=20.093 \mathrm{x}+239.70$, $\mathrm{r}=0.76)$ and $b^{*}(\mathrm{y}=64.763 \mathrm{x}+665.25, \mathrm{r}=0.80)$ the correlation achieved higher values. However, the correlation for all tested parameters was significant. With these equations and a high goodness of fit, the anthocyanin content after colour measurement could be predicted with a high degree of precision. Jiménez-Aguilar et al. (2011) observed similar results for blackberry powders.

The change of MD content in the powders obtained caused a decrease in the $a^{*}$ (greenness-redness) and $b^{*}$ (blueness-yellowness) parameters. This decrease was not statistically significant when MD was replaced with AG or when MD was replaced with starch (Table 4). For lightness $\left(L^{*}\right)$ no clear correlation was observed.

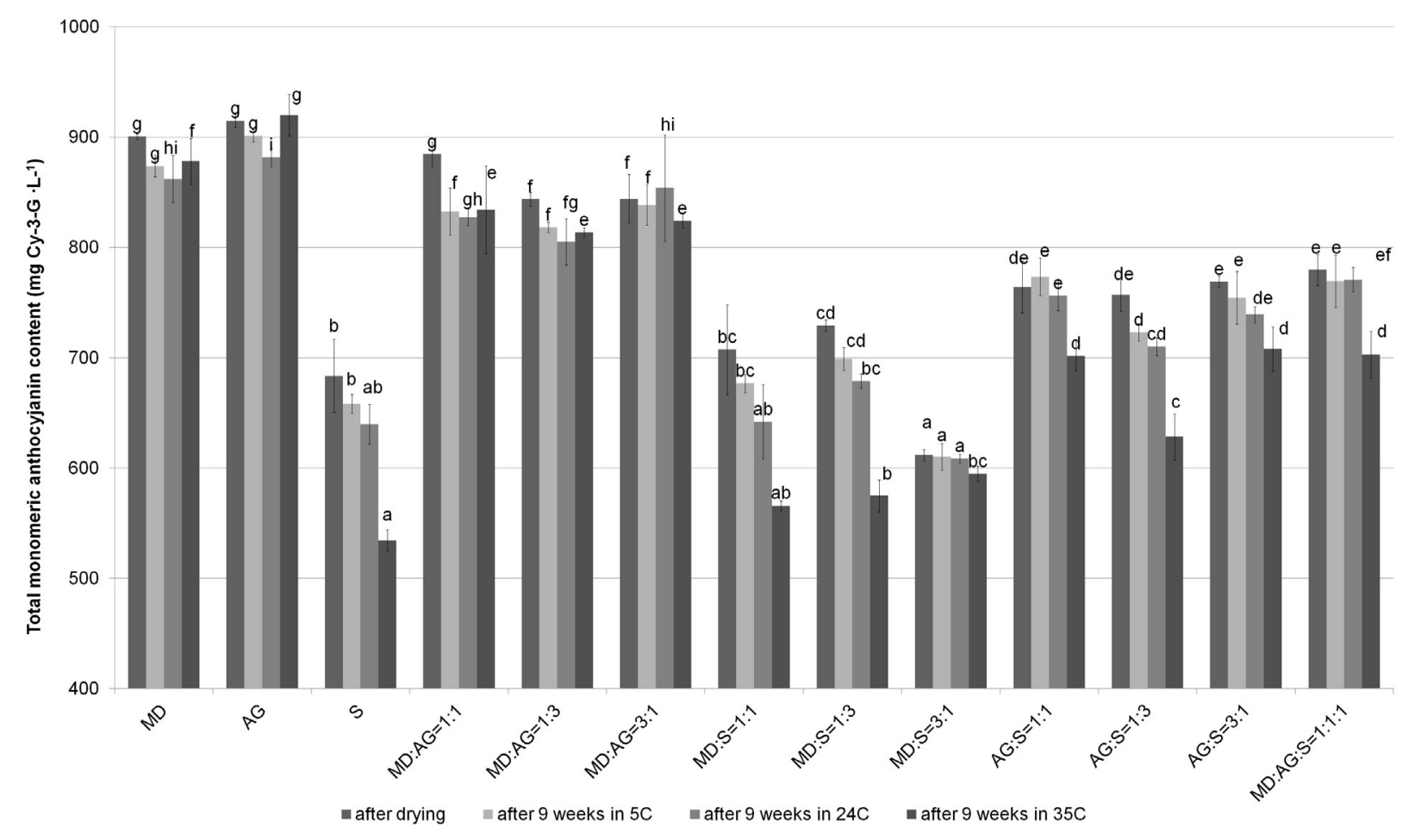

Fig. 3. Total monomeric anthocyanins content a,b,c,d - values denoted with different letters in the same tested parameter differ significantly $(\mathrm{p}<0.05)$. 
Table 4. Colour parameters of powders after drying and after storage in different conditions

\begin{tabular}{|c|c|c|c|c|c|c|c|c|c|c|c|}
\hline \multirow{2}{*}{\multicolumn{3}{|c|}{ After drying }} & \multicolumn{9}{|c|}{ After 9 weeks of storage } \\
\hline & & & \multicolumn{3}{|c|}{$5^{\circ} \mathrm{C}$} & \multicolumn{3}{|c|}{$25^{\circ} \mathrm{C}$} & \multicolumn{3}{|c|}{$35^{\circ} \mathrm{C}$} \\
\hline $\mathrm{L}^{*}$ & $a^{*}$ & $b^{*}$ & $\mathrm{~L}^{*}$ & $a^{*}$ & $b^{*}$ & $\mathrm{~L}^{*}$ & $a^{*}$ & $b^{*}$ & $\mathrm{~L}^{*}$ & $a^{*}$ & $b^{*}$ \\
\hline \multicolumn{12}{|l|}{ MD } \\
\hline $47.7 \pm 0.6$ & $32.0 \pm 1.0$ & $3.7 \pm 0.3$ & $47.2 \pm 0.2$ & $32.0 \pm 0.6$ & $4.1 \pm 0.3$ & $48.2 \pm 0.5$ & $32.5 \pm 0.3$ & $3.9 \pm 0.2$ & $48.7 \pm 0.2$ & $31.5 \pm 0.2$ & $3.8 \pm 0.1$ \\
\hline abcAB & fA & $\mathrm{fA}$ & $\mathrm{bcA}$ & gA & $\mathrm{gA}$ & $\mathrm{dBC}$ & hA & $\mathrm{iA}$ & $\mathrm{abcC}$ & fA & hA \\
\hline \multicolumn{12}{|c|}{$\mathrm{AG}$} \\
\hline $47.6 \pm 0.7$ & $29.8 \pm 0.5$ & $2.3 \pm 0.2$ & $47.6 \pm 0.1$ & $29.8 \pm 0.2$ & $2.5 \pm 0.1$ & $47.6 \pm 0.1$ & $30.2 \pm 0.3$ & $2.7 \pm 0.1$ & $47.9 \pm 0.6$ & $29.8 \pm 0.1$ & $2.5 \pm 0.1$ \\
\hline $\mathrm{abcA}$ & $\mathrm{eA}$ & $\mathrm{dA}$ & $\operatorname{cde} \mathrm{A}$ & $\mathrm{eA}$ & $\mathrm{dAB}$ & $\mathrm{bAc}$ & fA & $\mathrm{fB}$ & $\mathrm{aA}$ & $\mathrm{eA}$ & $\mathrm{eAB}$ \\
\hline \multicolumn{12}{|c|}{ S } \\
\hline $49.5 \pm 0$ & $25.2 \pm 0.1$ & $1.1 \pm 0.1$ & $49.5 \pm 03$ & $25.1 \pm 0.2$ & $1.3 \pm 0.1$ & $50.1 \pm 0.2$ & $25.1 \pm 0.1$ & $1.5 \pm 0.0$ & $51.2 \pm 0.6$ & $23.6 \pm 0.4$ & $1.7 \pm 0.1$ \\
\hline $7 \mathrm{dA}$ & $\operatorname{cdA}$ & $\mathrm{bcA}$ & gA & $\mathrm{cA}$ & $\mathrm{bB}$ & $\mathrm{gA}$ & $\operatorname{cdA}$ & $\mathrm{cC}$ & $\mathrm{eB}$ & $\mathrm{bB}$ & $\mathrm{dD}$ \\
\hline \multicolumn{12}{|c|}{ MD:AG=1:1 } \\
\hline $48.5 \pm 0.6$ & $31.7 \pm 0.6$ & $3.3 \pm 0.2$ & $48.1 \pm 0.1$ & $32.1 \pm 0.1$ & $3.6 \pm 0.2$ & $48.7 \pm 0.1$ & $32.7 \pm 0.2$ & $3.7 \pm 0.1$ & $49.5 \pm 0.3$ & $31.8 \pm 0.3$ & $3.6 \pm 0.1$ \\
\hline cdAB & fAB & efA & $\operatorname{defA}$ & gA & $\mathrm{fB}$ & $\mathrm{fB}$ & $\mathrm{hB}$ & iB & $\mathrm{cdC}$ & $\mathrm{fC}$ & ghB \\
\hline \multicolumn{12}{|c|}{$\mathrm{MD}: \mathrm{AG}=1: 3$} \\
\hline $48.3 \pm 0.7$ & $31.0 \pm 1.2$ & $3.3 \pm 0.6$ & $48.6 \pm 0.1$ & $31.0 \pm 0.1$ & $3.4 \pm 0.4$ & $48.9 \pm 0.4$ & $31.4 \pm 0.1$ & $3.5 \pm 0.3$ & $49.2 \pm 0.1$ & $30.9 \pm 0.1$ & $3.4 \pm 0.5$ \\
\hline $\mathrm{cA}$ & $\mathrm{fA}$ & efA & b-eAB & $\mathrm{fA}$ & efA & fAB & gA & $\mathrm{hA}$ & $\mathrm{bcB}$ & fA & gA \\
\hline \multicolumn{12}{|c|}{ MD:AG=3:1 } \\
\hline $47.5 \pm 0.7$ & $31.3 \pm 0.5$ & $2.9 \pm 0.2$ & $47.6 \pm 0.1$ & $31.4 \pm 0.2$ & $3.1 \pm 0.1$ & $47.9 \pm 0.1$ & $31.7 \pm 0.3$ & $3.2 \pm 0.1$ & $47.9 \pm 0.6$ & $31.5 \pm 0.1$ & $3.0 \pm 0.1$ \\
\hline$a b c A$ & fA & eA & fA & fA & $\mathrm{eA}$ & $\operatorname{cdA}$ & gA & gA & $\mathrm{aA}$ & fA & fA \\
\hline \multicolumn{12}{|c|}{$\mathrm{MD}: \mathrm{S}=1: 1$} \\
\hline $46.7 \pm 0.5$ & $23.7 \pm 0.4$ & $1.5 \pm 0.1$ & $46.6 \pm 0.1$ & $23.8 \pm 0.1$ & $1.7 \pm 0.1$ & $46.4 \pm 0.3$ & $23.7 \pm 0.2$ & $1.9 \pm 0.1$ & $48.6 \pm 1.2$ & $22.4 \pm 1.4$ & $1.2 \pm 0.1$ \\
\hline $\mathrm{aA}$ & $\mathrm{abA}$ & $\mathrm{cB}$ & $\mathrm{aA}$ & $\mathrm{aA}$ & $\mathrm{cC}$ & $\mathrm{aA}$ & $\mathrm{aA}$ & $\mathrm{eD}$ & $\mathrm{abcB}$ & $\mathrm{aB}$ & $\mathrm{bcA}$ \\
\hline \multicolumn{12}{|c|}{$\mathrm{MD}: \mathrm{S}=1: 3$} \\
\hline $46.9 \pm 0.8$ & $23.4 \pm 0.2$ & $1.5 \pm 0.3$ & $47.0 \pm 0.3$ & $23.7 \pm 0.2$ & $1.6 \pm 0.2$ & $47.3 \pm 0.3$ & $24.1 \pm 0.2$ & $1.8 \pm 0.1$ & & & \\
\hline $\mathrm{abA}$ & $\mathrm{aA}$ & $\mathrm{cA}$ & $\mathrm{abA}$ & $\mathrm{aB}$ & bcAB & $\mathrm{bA}$ & $\mathrm{bC}$ & deB & $\mathrm{Bd}$ & $\mathrm{Bd}$ & $\mathrm{Bd}$ \\
\hline \multicolumn{12}{|c|}{$\mathrm{MD}: \mathrm{S}=3: 1$} \\
\hline $52.8 \pm 0.4$ & $25.7 \pm 0.1$ & $0.3 \pm 0.1$ & $53.2 \pm 0.3$ & $26.2 \pm 0.2$ & $0.4 \pm 0.1$ & $53.1 \pm 0.4$ & $26.6 \pm 0.1$ & $0.5 \pm 0.1$ & $53.6 \pm 0.6$ & $25.9 \pm 0.1$ & $0.5 \pm 0.1$ \\
\hline $\mathrm{eA}$ & $\mathrm{dA}$ & $\mathrm{aA}$ & hAB & $\mathrm{dB}$ & $\mathrm{aAB}$ & $\mathrm{hAB}$ & $\mathrm{eC}$ & $\mathrm{aB}$ & $\mathrm{fB}$ & $\mathrm{dA}$ & $\mathrm{aAB}$ \\
\hline \multicolumn{12}{|c|}{$\mathrm{AG}: \mathrm{S}=1: 1$} \\
\hline $48.0 \pm 0.1$ & $24.6 \pm 0.2$ & $1.1 \pm 0.1$ & $48.1 \pm 0.1$ & $24.9 \pm 0.2$ & $1.3 \pm 0.0$ & $48.3 \pm 0.1$ & $25.2 \pm 0.1$ & $1.4 \pm 0.0$ & $48.5 \pm 0.1$ & $24.2 \pm 0.3$ & $1.3 \pm 0.1$ \\
\hline $\mathrm{bcA}$ & $\mathrm{bcB}$ & $\mathrm{bcA}$ & efAB & $\mathrm{bcBC}$ & $\mathrm{bB}$ & $\mathrm{deB}$ & $\mathrm{cdC}$ & $\mathrm{cB}$ & $\mathrm{abC}$ & $\mathrm{bcA}$ & $\mathrm{cB}$ \\
\hline \multicolumn{12}{|c|}{$\mathrm{AG}: \mathrm{S}=1: 3$} \\
\hline $47.9 \pm 0.2$ & $24.6 \pm 0.1$ & $1.1 \pm 0.0$ & $47.5 \pm 0.3$ & $24.8 \pm 0.1$ & $1.4 \pm 0.1$ & $47.9 \pm 0.1$ & $25.0 \pm 0.1$ & $1.4 \pm 0.0$ & $48.5 \pm 0.1$ & $24.2 \pm 0.3$ & $1.3 \pm 0.1$ \\
\hline $\mathrm{bcB}$ & $\mathrm{bcB}$ & $\mathrm{abA}$ & bcdA & $\mathrm{bcBC}$ & $\mathrm{bBC}$ & $\mathrm{cdB}$ & $\mathrm{cC}$ & $\mathrm{cC}$ & $\mathrm{abC}$ & $\mathrm{bcA}$ & $\mathrm{cB}$ \\
\hline \multicolumn{12}{|c|}{$\mathrm{AG}: \mathrm{S}=3: 1$} \\
\hline $49.5 \pm 0.2$ & $24.8 \pm 0.2$ & $0.6 \pm 0.1$ & $49.9 \pm 0.4$ & $24.7 \pm 0.2$ & $0.7 \pm 0.1$ & $49.9 \pm 0.2$ & $25.3 \pm 0.1$ & $1.0 \pm 0.1$ & $50.2 \pm 0.2$ & $24.9 \pm 0.0$ & $0.9 \pm 0.0$ \\
\hline $\mathrm{dA}$ & bcdA & $\mathrm{abA}$ & $\mathrm{gB}$ & $\mathrm{bA}$ & $\mathrm{aAB}$ & gAB & $\mathrm{dB}$ & $\mathrm{bC}$ & $\mathrm{dB}$ & $\mathrm{cA}$ & $\mathrm{bB}$ \\
\hline \multicolumn{12}{|c|}{ MD:AG:S=1:1:1 } \\
\hline $47.8 \pm 0.6$ & $24.2 \pm 0.2$ & $1.2 \pm 0.2$ & $47.3 \pm 0.2$ & $24.6 \pm 0.1$ & $1.5 \pm 0.1$ & $47.9 \pm 0.1$ & $25.1 \pm 0.1$ & $1.5 \pm 0.0$ & $48.7 \pm 0.2$ & $24.3 \pm 0.2$ & $1.4 \pm 0.1$ \\
\hline abcAB & $\mathrm{abA}$ & $\mathrm{cA}$ & bcA & $\mathrm{bB}$ & $\mathrm{bcB}$ & $\mathrm{cdB}$ & $\mathrm{cdC}$ & $\mathrm{cB}$ & $\mathrm{abcC}$ & $\mathrm{bcA}$ & $\mathrm{cdB}$ \\
\hline
\end{tabular}

Explanations as in Table 2. 
After storage for 9 weeks, the values of parameters $L^{*}$, $a^{*}$ and $b^{*}$ did not differ statistically significantly in most cases from powders after drying (Table 4). Moreover, for all powders some statistically significant parameter $b^{*}$ increase was observed. The exception were the powders containing MD or a higher percentage of the substance in the carrier mixture $(75 \%)$. This may be related to the low level of oxidation of anthocyanins from the outer layer of powders and the improved protection afforded by MD as a carrier material (Janiszewska, 2014; Jiménez-Aguilar et al., 2011).

Anthocyanins are very unstable and highly susceptible to degradation during storage. The rate of degradation is dependent on various factors such as temperature, light, time and the nature of the type of processing applied (Presilski et al., 2016). Moreover, the chemical structure of anthocyanins may cause its degradation during storage.

In our studies, after 9 weeks of storage at three different temperatures $\left(5,25\right.$ and $\left.35^{\circ} \mathrm{C}\right)$, it could be observed that that the most advanced degradation occurred at the highest temperature (3, 5 and $11 \%$, respectively) (Fig. 3). A statistically significant decrease in total monomeric anthocyanins was found with the increase in storage temperature. However, the decrease at lower storage temperatures was lower than it was for a temperature of $35^{\circ} \mathrm{C}$.

The carrier material influenced the anthocyanin content during storage (Fig. 3). A statistically significant decrease, at a temperature of $5^{\circ} \mathrm{C}$, was observed for powders $\mathrm{MD}$, $\mathrm{MD}: \mathrm{AG}=1: 1, \mathrm{MD}: \mathrm{AG}=1: 3, \mathrm{MD}: \mathrm{S}=1: 3$ and $\mathrm{AG}: \mathrm{S}=1: 3$, while at a temperature of $25^{\circ} \mathrm{C}$ the majority of powders were characterized by a decrease in the anthocyanin content. For all of the tested carriers only powders with AG did not show a statistically significant decrease during storage at $35^{\circ} \mathrm{C}$. The largest decrease was observed for powders with starch and starch mixtures with maltodextrin, this occurred independently of its content.

In addition, it was found that the anthocyanin content during storage was higher for carrier materials with $A G$ in comparison to those with MD. Tonon et al. (2010) stated that the content of anthocyanins in powders of acai berry juice with $\mathrm{MD}$ as a carrier did not differ significantly from their content in dried materials, in which the carrier was arabic gum. The best retention of anthocyanins was obtained for maltodextrin with DE 10, then in arabic gum, and the lowest with the use of maltodextrin with DE 20 and tapioca starch (Tonon et al., 2010). These findings were confirmed by our results. The lowest retention of anthocyanin in starch may be explained by the low solubility of starch as it does not form capsules around the juice, and facilitates the drying process only as a carrier (Tonon et al., 2010).

The more rapid degradation of anthocyanin at higher temperatures may result from, among other causes, the presence of sugars and proteins that are involved in the non-enzymatic browning reaction. In acai berry juice the half-life of anthocyanins at $35^{\circ} \mathrm{C}$ was higher than that obtained at a storage temperature of $25^{\circ} \mathrm{C}$ (Tonon et al., 2010). The powders of purple carrot during storage at $4^{\circ} \mathrm{C}$ remained quite stable - the average losses were $11 \%$ by the end of the storage period, while at $25^{\circ} \mathrm{C}$ they were $33 \%$ (Ersus and Yurdagel, 2007).

\section{CONCLUSIONS}

1. The best carriers were considered to be pure maltodextrin and arabic gum, due to the high content of anthocyanin after drying and storage.

2. One of the lowest hygroscopicity values and the lowest water content values characterized powder based solely on maltodextrin, and its colour parameters $\left(a^{*}\right.$ and $\left.b^{*}\right)$ were among the highest recorded in this study.

3. Certain carriers, such as mixtures of maltodextrin and arabic gum, are certainly worthy of attention and further research, because the powders based on them showed interesting features, such as a lower porosity, hygroscopicity and a higher degree of stability than maltodextrin alone.

4. The use of starch as a carrier and protection material did not produce powders characterized with such high retention values as maltodextrin and arabic gum. Moreover, during storage the highest degree of degradation of the active ingredient was observed.

Conflict of interest: The Authors do not declare conflict of interest.

\section{REFERENCES}

Bazaria B. and Kumar P., 2016. Effect of whey protein concentrate as drying aid and drying parameters on physicochemical and functional properties of spray dried beetroot juice. Food Biosci., 14, 21-27. https://doi.org/10.1016/j.fbio.2015.11.002

Cavalcanti R.N., Santos D.T., and Meireles M.A.A., 2011. Non-thermal stabilization mechanisms of anthocyanins in model and food systems - An overview. Food Res. Int., 44, 499-509. https://doi.org/10.1016/j.foodres.2010.12.007

Chranioti C., Nikoloudaki A., and Tzia C., 2015. Saffron and beetroot extracts encapsulated in maltodextrin, gum Arabic, modified starch and chitosan: Incorporation in a chewing gum system, Carbohyd. Polym., 127, 252-263. https://doi.org/10.1016/j.carbpol.2015.03.049

Costa S.S., Machado B.A.S., Martin A.R., Bagnara F., Ragadalli S.A., and Alves A.R.C., 2015. Drying by spray drying in the food industry: Micro-encapsulation, process parameters and main carriers used. African J. Food Sci., 9, 462-470. https://doi.org/10.5897/ajfs2015.1279

Cujic N., Kardum N., Šavikin K., Zdunic G., Jankovic T., and Menkovic N., 2017. Potential of Chokeberry (Aronia melanocarpa L.) as a Therapeutic Food. In: Handbook of Food Bioengineering (Eds A.M. Holban, A.M. Grumezescu). Andre Gerhard Wolff, Romania 209-237. https://doi.org/10.1016/b978-0-12-811517-6.00007-6

Da Silva Carvalho A.G., da Costa Machado M.T., da Silva V.M, Sartoratto A., Rodrigues R.A.F., and Hubinger 
M.D., 2016. Physical properties and morphology of spray dried microparticles containing anthocyanins of jussara (Euterpe edulis Martius) extract. Powder Technol., 294, 421-428. https://doi.org/10.1016/j.powtec.2016.03.007

Domian E., Brynda-Kopytowska A. Cenkier J., and Świrydow E., 2015. Selected properties of microencapsulated oil powders with commercial preparations of maize OSA starch and trehalose. J. Food Eng., 152, 72-84.

https://doi.org/10.1016/j.jfoodeng.2014.09.034

Ersus S. and Yurdagel U., 2007. Microencapsulation of anthocyanin pigments of black carrot (Daucus carota L.) by spray drier. J, Food Eng., 80, 805-812. https://doi.org/10.1016/j. jfoodeng.2006.07.009

Fazaeli M., Emam-Djomeh Z., Kalbasi Ashtari A., and Omid M., 2012. Effect of spray drying conditions and feed composition on the physical properties of black mulberry juice powder. Food Bioprod. Process., 90, 667-675. https://doi.org/10.1016/j.fbp.2012.04.006

Gawalek J., Domian E., Ryniecki A., and Bakier S., 2017. Effects of the spray drying conditions of chokeberry (Aronia melanocarpa L.) juice concentrate on the physicochemical properties of powders. Inter. J. Food Sci. Technol., 52(9), 1933-1941. https://doi.org/10.1111/ijfs. 13476

Giusti M.M. and Wrolstad R.E., 2001. Characterization and measurement of anthocyanins by UV - visible spectroscopy. In: Current Protocols in Food Analytical Chemistry (Ed. R.E. Wrolstad). J. Wiley \& Sons, New York, F1.2.1F1.2.13. https://doi.org/10.1002/0471142913.faf0102s00

Horszwald A., Julien H., and Andlauer W., 2013. Characterisation of aronia powders obtained by different drying processes. Food Chem., 141, 2858-2863. https://doi.org/10.1016/j.foodchem.2013.05.103

Jafari S.M., Ghalenoei M.G., and Dehnad D., 2017. Influence of spray drying on water solubility index, apparent density, and anthocyanin content of pomegranate juice powder. Powder Technol., 311, 59-65. https://doi.org/10.1016/j.powtec.2017.01.070

Janiszewska E., 2014. Microencapsulated beetroot juice as a potential source of betalain. Powder Technol., 264, 190-196. https://doi.org/10.1016/j.powtec.2014.05.032

Janiszewska E., Śliwińska D., and Witrowa-Rajchert D., 2010. Effect of lemon aroma content on selected physical properties of microcapsules (in Polish). Acta Agrophysica, 16(1), 59-68.

Janiszewska E., Witrowa-Rajchert D., Czapski J., and Kidoń M., 2013. The effect of the applied drying method on physical properties of purple carrot pomace. Int. Agrophys., 27(2), 143-149. https://doi.org/10.2478/v10247-012-0079-6
Janiszewska-Turak E., Dellarosa N., Tylewicz U., Laghi L., Romani S., Dalla Rosa M., and Witrowa-Rajchert D., 2017. The influence of carrier material on some physical and structural properties of carrot juice microcapsules. Food Chem., 236, 134-141. https://doi.org/10.1016/j.foodchem.2017.03.134

Jiménez-Aguilar D.M., Ortega-Regules A.E., Lozada-Ramírez J.D., Pérez-Pérez M.C.I., Vernon-Carter E.J., and WeltiChanes J., 2011. Color and chemical stability of spray-dried blueberry extract using mesquite gum as wall material. J. Food Composition Anal., 24(6), 889-894. https://doi.org/10.1016/j.jfca.2011.04.012

Oszmiański J. and Wojdyło A., 2005. Aronia melanocarpa phenolics and their antioxidant activity. Europ. Food Res. Technol., 221(6), 809-813. https://doi.org/10.1007/s00217-005-0002-5

Phisut N., 2012. Spray drying technique of fruit juice powder: some factors influencing the properties of product. Int. Food Res. J., 19, 1297-1306.

Presilski S., Presilska N., and Tomovska D., 2016. Effects of extraction, conventional processing and storage on natural anthocyanins. J. Food Process. Technol., 7(2), 2-4. https:// doi.org/10.4172/2157-7110.1000551

Rodriguez-Mateos A., Heiss C., Borges G., and Crozier A., 2014. Berry (poly) phenols and cardiovascular health. J. Agric. Food Chem., 62(18), 3842-3851. https://doi.org/10.1021/jf403757g

Roos Y.H., 2002. Importance of glass transition and water activity to spray drying and stability of dairy powders. Le Lait., 82(4), 475-484.

Samoticha J., Wojdyło A., and Lech K., 2016. The influence of different the drying methods on chemical composition and antioxidant activity in chokeberries. LWT-Food Sci. Technol., 66, 484-489. https://doi.org/10.1016/j.lwt.2015.10.073

Tonon R.V., Brabet C., and Hubinger M.D., 2010. Anthocyanin stability and antioxidant activity of spray-dried acai (Euterpeoleraceae Mart.) juice produced with different carrier agents. Food Res. Int., 43, 907-914. https://doi.org/10.1016/j.foodres.2009.12.013

Veberic R., Slatnar A., Bizjak J., Stampar F., and MikulicPetkovsek M., 2015. Anthocyanin composition of different wild and cultivated berry species. LWT-Food Sci. Technol., 60(1), 509-517. https://doi.org/10.1016/j.lwt.2014.08.033

Yamashita C., Chung M.M.S., dos Santos C., Mayer C.R.M., Moraes I.C.F., and Branco I.G., 2017. Microencapsulation of an anthocyanin-rich blackberry (Rubus spp.) by-product extract by freeze-drying. LWT-Food Sci. Technol., 84, 256-262. https://doi.org/10.1016/j.lwt.2017.05.063 